\title{
Correction to: Special issue title: Optimization and mathematical modeling in energy systems
}

\author{
Georgios K. D. Saharidis ${ }^{1}$ (D) $\cdot$ Zoi Moza $^{1} \cdot$ Mihalis Golias $^{2}$
}

Published online: 23 October 2021

(c) The Author(s), under exclusive licence to Springer-Verlag GmbH Germany, part of Springer Nature 2021

\section{Correction to: Energy Systems https://doi.org/10.1007/s12667-021-00443-x}

In the original publication of the article, four articles already published to other issues were incorrectly included. These articles are:

1. Nikolaidis, Pavlos \& Chatzis, Sotirios \& Poullikkas, Andreas. (2020). Optimal planning of electricity storage to minimize operating reserve requirements in an isolated island grid. Energy Systems. 11. https://doi.org/10.1007/s12667-01900355-X.

2. Touš, Michal \& Máša, Vítězslav \& Vondra, Marek. (2021). Energy and water savings in military base camps. Energy Systems. https://doi.org/10.1007/s12667019-00354-y.

3. Atsalakis, George \& Frantzis, Dimitrios \& Zopounidis, Constantin. (2015). Energy's exports forecasting by a neuro-fuzzy controller. Energy Systems. 6. https:// doi.org/10.1007/s12667-015-0140-1.

4. Nazari, Amirali \& Keypour, Reza. (2020). Participation of responsive electrical consumers in load smoothing and reserve providing to optimize the schedule of a typical microgrid. Energy Systems. 11. https://doi.org/10.1007/s12667-01900349-9.

The special issue does not contain the above papers.

Publisher's Note Springer Nature remains neutral with regard to jurisdictional claims in published maps and institutional affiliations.

The original article can be found online at https://doi.org/10.1007/s12667-021-00443-x.

Georgios K. D. Saharidis

saharidis@gmail.com

1 Department of Mechanical Engineering, University of Thessaly, Volos, Greece

2 Department of Civil Engineering, University of Memphis, Memphis, TN, USA 